\title{
Differential Effects of Mild and Severe Cucumber mosaic virus Strains in the Perturbation of MicroRNA-Regulated Gene Expression in Tomato Map to the 3' Sequence of RNA 2
}

\author{
Fabrizio Cillo, Tiziana Mascia, Marco M. Pasciuto, and Donato Gallitelli \\ Istituto di Virologia Vegetale, CNR, and Dipartimento di Protezione delle Piante e Microbiologia Applicata, Università \\ degli Studi di Bari, Via Amendola 165/A, 70126 Bari, Italy
}

Submitted 5 May 2009. Accepted 16 June 2009.

\begin{abstract}
Viral infections interfere with the microRNA (miRNA)-mediated regulation of gene expression, determining developmental defects. In tomato leaves, the accumulation levels of six miRNA species and their target transcripts corresponding to transcription factors with roles in plant development and leaf morphogenesis and two genes involved in the short RNA processing, $D C L 1$ and $A G O 1$, were significantly enhanced upon infection with the severe strain Cucumber mosaic virus (CMV)-Fny, while that of $\mathrm{AGO} 4$ was reduced. In plants harboring the infection of the mild strain CMVLS , the effects on miRNA pathway were reduced, although $A G O 1, D C L 1$, and NAC1 also were shown to overaccumulate during infections exhibiting a mild phenotype. The use of the recombinant strain CMV-Fny(LS2b), in which the 3 '-terminal region of CMV-Fny RNA 2, including the $2 b$ coding sequence, was replaced with the corresponding region of CMV-LS RNA 2, provided evidence that the exchanged region was implicated in the perturbation of miRNA metabolism. In tomato plants infected with CMVFny supporting the ameliorative satellite (sat)RNA variant Tfn-satRNA, the symptomless phenotype correlated, with the exception of NAC1 upregulation, with the absence of effects on mitochondrial RNA and miRNA expression. Some of the aspects of miRNA pathway perturbation described were peculiar to CMV-tomato interactions and involved in the etiology of the disease phenotype elicited in this host.
\end{abstract}

Plants possess different RNA-silencing pathways based on small RNAs, and this diversity is exploited for the regulation of a number of physiological functions, including regulation of gene expression and control of viruses, invasive elements, and repeated sequences (Chapman and Carrington 2007). MicroRNA (miRNA) metabolism is an RNA-silencing pathway that controls endogenous gene expression (Jones-Rhoades et al. 2006). It starts with the processing of approximately $1-\mathrm{kb}$ miRNA precursors in the nucleus (pri-miRNAs), which produce imperfectly paired double-stranded (ds)RNAs of approximately 70 nucleotides (nt) (pre-miRNAs) that serve as sub-

Corresponding author: Fabrizio Cillo; E-mail: f.cillo@ba.ivv.cnr.it

Current address for T. Mascia and D. Gallitelli: Dipartimento di Biologia e Patologia Vegetale, Università degli Studi di Bari, Via Amendola 165/A, 70126 Bari, Italy. strate for Dicer-like proteins (DCL1 in Arabidopsis thaliana) for the production of mature 21- to 22-nt miRNAs. Sense miRNAs are then incorporated in the RNA-induced silencing complex (RISC), a ribonucleoprotein complex including Argonaute proteins (AGO1 in A. thaliana), and target for degradation complementary endogenous mitochondrial (m)RNAs in a sequence-specific manner, while minus-sense miRNAs, or miRNA*, are very unstable and quickly degraded in the cytoplasm (Jones-Rhoades et al. 2006).

Small interfering RNAs (siRNAs) are chemically similar to miRNAs but show a size range between 21 and $24 \mathrm{nt}$ (Hamilton et al. 2002; Llave et al. 2002). SiRNAs are processed from precursors containing dsRNA structure, such as transcripts containing inverted repeats or intermediates formed during RNA virus replication, and, therefore, are part of the RNA-silencing pathway operating as a defense of hosts against invading or noxious nucleic acids (Voinnet 2005). There is substantial overlapping between miRNA- and siRNA-dependent RNA-silencing pathways: for instance, virus-derived dsRNA are reduced to small 21- to 24-nt dsRNAs by DCL proteins such as DCL2 and DCL4 in A. thaliana (Aliyari and Ding 2009), and then siRNAs complementary to viral targets are recruited by AGOs (AGO1 and AGO7 in A. thaliana) (Qu et al. 2008) and incorporated into the RISC for sequence-specific viral RNA cleavage.

Most plant viruses are able to counteract the siRNA-mediated antiviral immune system by expressing proteins that block or interfere to some extent with RNA silencing (Palukaitis and MacFarlane 2006; Voinnet 2005). Because there are so many common features shared between the siRNA and miRNA pathways, an outcome of the viral RNA silencing-suppression activity is the alteration of miRNA metabolism that some authors interpreted as a side effect of the antiviral silencing suppression (Dunoyer et al. 2004; Qu and Morris 2005), although functions as a type of adaptive response or a mechanism beneficial to viral infection cannot be ruled out. A number of modifications in the normal miRNA-dependent gene expression regulation have been observed by both expressing viral silencing suppressors in transgenic plants and inoculating plants with viruses. These modifications have been proposed to include direct interaction between viral silencing suppressors and AGO1; functional inactivation of RISC complexes; and overaccumulation of stabilized and inactive miRNA/miRNA* duplexes, null or reduced miRNA-guided cleavage, and consequent upregulation of host target mRNAs (Chapman et al. 2004; Zhang et al. 2006; Bazzini et al. 2007; Lewsey et al. 2007; Shiboleth et al. 2007; Tagami et al. 2007). 
Because DCLI and $A G O 1$ are themselves post-transcriptionally regulated by miRNAs (miR162 and miR168, respectively) through a negative feedback mechanism controlling their expression, miRNA pathway perturbation also may lead to the significant increase of their accumulation levels (Zhang et al. 2006). However, miRNA target genes in plants are preferentially transcription factors (TF) which, in fact, account for over $65 \%$ the predicted targets in A. thaliana (Rhoades et al. 2002). Most of the targeted TF are known to regulate plant tissue and organ development, suggesting that miRNAs play a central role in the coordination of a wide range of cell division and cell fate decisions throughout the plant (Rhoades et al. 2002). Organogenesis from meristems and leaf morphogenesis, for instance, depends on the participation of several miRNAs that work as a synchronized network determining spatial and temporal regulation of gene expression. MiR164, miR165/166, and miR319, with their respective targets belonging to the NAC, HD-ZIP, and TCP families of TF, are among the essential regulators of meristem initiation and maintenance, axillary meristem differentiation, and leaf morphology, together with another numerous family of $\mathrm{TF}$, the auxin response factor $(A R F)$ genes, that are targeted by both miR167 and another family of small RNA regulators known as trans-acting siRNAs (Chuck et al. 2009). Modifications of the complex equilibrium of miRNAdependent TF expression, such as the virus-induced disruption of the miRNA pathway, are then expected to manifest with clear phenotypes involving defects of plant development.

Different viral silencing-suppressor proteins have been associated with phenomena of miRNA pathway alteration including, among others, the P1/HCPro of different Potyvirus spp., Potato virus $X \mathrm{p} 25$, Tomato bushy stunt virus $\mathrm{p} 19$, Turnip crinkle virus coat protein, and the $2 \mathrm{~b}$ protein of Cucumber mosaic virus (CMV). Interestingly, transgenic expression in Arabidopsis of the $2 \mathrm{~b}$ protein from mild CMV strains did not induce disruption of the miRNA pathway (Chapman et al. 2004; Zhang et al. 2006; Lewsey et al. 2007), whereas expression of the $2 \mathrm{~b}$ protein from a severe strain, in addition to inducing a symptom-like phenotype in transgenic plants, also showed altered accumulation levels of miRNAs and miRNA-regulated genes (Zhang et al. 2006; Lewsey et al. 2007).

According to molecular and serological features, CMV strains are currently classified into three subgroups indicated as IA,

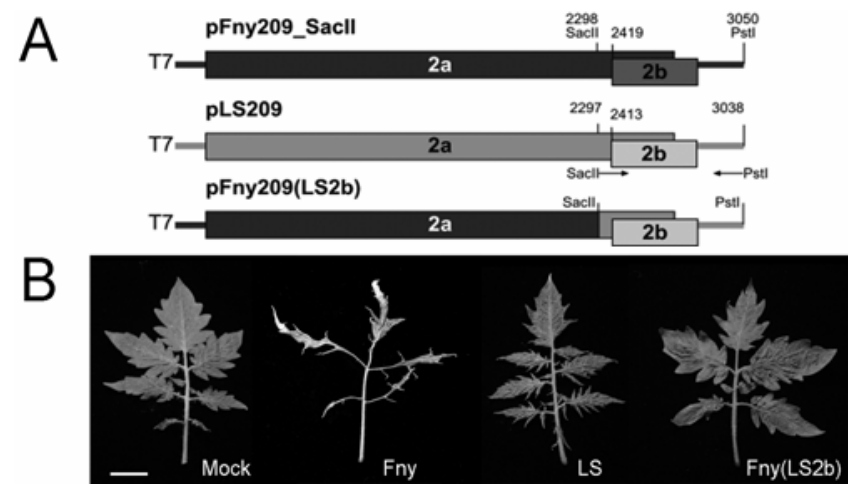

Fig. 1. Wild-type and recombinant Cucumber mosaic virus (CMV) strains show different pathogenicity on tomato plants. A, Schematic representation of CMV RNA2 vectors used in this work. cDNAs corresponding to CMV-Fny and CMV-LS RNA2s are cloned in pFny209 and pLS209, respectively. The vector pFny209(LS2b) was obtained by substituting a 741bp region of pLS209, that includes the C-terminus of the 2a protein, the complete $2 \mathrm{~b}$ protein, the $2 \mathrm{a} / 2 \mathrm{~b}$ overlapping fragment, and the $3^{\prime}$ untranslated region, to the corresponding region of CMV-Fny. B, Effects of decreasing severity on leaf morphology in tomato cv. UC82 are displayed upon infection with CMV-Fny, CMV-LS, and CMV-Fny(LS2b). Scale bar represents $1 \mathrm{~cm}$.
IB, and II (Palukaitis and Garcia-Arenal 2003). The CMV genome is constituted by three linear, plus-sense, singlestranded RNAs (RNAs 1, 2, and 3) and the subgenomic RNAs 4 and $4 \mathrm{~A}$, which contain five genes encoding proteins designated 1a, 2a, 2b, 3a, and 3b (Palukaitis and Garcia-Arenal 2003). The CMV $2 b$ is a multifunctional and well-characterized protein of approximately $12 \mathrm{kDa}$, encoded by a sequence located at the $3^{\prime}$ end of RNA 2 that overlaps, on a different reading frame, the $3^{\prime}$ end of the $2 a$ gene. It is expressed from RNA 4A, a subgenomic RNA derived from RNA 2 (Ding et al. 1994). The $2 \mathrm{~b}$ proteins from CMV and another member of the Cucumovirus genus, Tomato aspermy virus, were shown to function as suppressors of post-transcriptional gene silencing (Beclin et al. 1998; Brigneti et al. 1998; Li et al. 1999). The $2 \mathrm{~b}$ serves as a determinant for viral long-distance transport (Ding et al. 1995; Ji and Ding 2001; Soards et al. 2002; Wang et al. 2004), as well as for local cell-to-cell movement (Soards et al. 2002; Shi et al. 2003). Moreover, 2b represents the major virus pathogenicity determinant, as demonstrated by replacing the $2 b$ gene of a mild CMV strain with that of a more severe one or by deleting the $2 b$ gene sequence obtaining a symptomless infection (Ding et al. 1996; Shi et al. 2002; Soards et al. 2002). Thus, the difference in virulence observed between the severe subgroup IA strain CMV-Fny and the mild subgroup II strain CMV-LS on different hosts (Zhang et al. 1994; Wang et al. 2002) also could be determined, in addition to other viral factors, by differences in the respective $2 \mathrm{~b}$ protein sequences.

In the present work, we used a system based on a chimeric CMV inoculum to investigate the role of $2 b$ and adjacent RNA 2 sequences in perturbing miRNA pathways in tomato in the course of CMV infections. We found that, unlike what previously was observed in 2b-transgenic Arabidopsis (Lewsey et al. 2007), both CMV-Fny and CMV-LS provoked significant changes in the miRNA-regulated expression of several genes. We also demonstrated that TF having a key role in leaf morphogenesis, and corresponding miRNAs that post-transcriptionally regulate their turnover, overaccumulated specifically during CMV-Fny infections but not during either mild CMV infections or when CMV-Fny was inoculated together with a mild variant of satellite (sat)RNA co-determining symptomless infections on tomato.

\section{RESULTS}

Infectivity, symptoms, and RNA accumulation levels of severe, mild, and recombinant CMV strains.

We constructed a chimeric infectious clone in the background of CMV-Fny RNA 2, in which its 3' terminus was replaced with a homologous fragment derived from CMV-LS RNA 2. Nucleotide sequence analysis showed that the resulting pFny209(LS2b) clone contained a recombinant cDNA joining fragments 1 to 2,296 from CMV-Fny RNA 2 and 2,297 to 3,041 from CMV-LS RNA 2. It putatively coded for a chimeric 2 a protein consisting of the $736 \mathrm{~N}$-terminal amino acids from CMV-Fny and the 106 C-terminal amino acids from CMV-LS, in addition to the $2 \mathrm{~b}$ protein entirely derived from CMV-LS (Fig. 1A). The recombinant strain CMV-Fny(LS2b) was recostituted in tomato plants inoculated with infectious transcripts of CMV-Fny RNAs 1 and 3 plus the chimeric RNA 2 derived from the transcription of pFny209(LS2b).

CMV-Fny(LS2b), its parental strains CMV-Fny and CMVLS, and the combination of CMV-Fny supporting the ameliorative variant of the satRNA from CMV-Tfn (Tfn-satRNA) were inoculated onto tomato plants to compare symptoms development and viral RNA accumulation. As the first step, tomato plants infected with the different CMV inocula were 
monitored for disease symptoms between 12 and 14 days postinoculation (dpi). CMV-Fny severely altered leaf morphogenesis, inducing the typical reduction of leaflet blades (Fig. $1 \mathrm{~B}$, shoestring leaf) and of whole-plant growth. CMV-LS infection induced a moderate leaf blade reduction not associated with decrease of plant size (Fig. 1B). CMV-Fny(LS2b) infected tomato plants systemically, eliciting very mild symptoms consisting of moderate bubbling of leaflet blades (Fig. 1B), with no other evident alteration of whole-plant morphology. The genetic stability of the recombinant CMV-Fny(LS2b) RNA 2 was assessed at $30 \mathrm{dpi}$ by reverse-transcription polymerase chain reaction (RT-PCR) amplification of a 900-bp DNA fragment corresponding to the 3 '-terminal region of RNA 2 using a forward primer designed on a region of CMV-Fny approximately $150 \mathrm{nt}$ upstream from the recombination breakpoint. Three of these DNA fragments deriving from three individual plants were directly sequenced, showing no sequence variations from the original cDNA clone (not shown). The infection of CMV-Fny/Tfn-satRNA, as expected, showed a symptomless phenotype on tomato (not shown).

As the second step, the RNA accumulation profiles of the four inocula in infected tomato plants were examined. Samples were collected from the systemically infected leaves at 9 dpi. The levels of accumulation of CMV RNAs 2 and 3 in these leaf tissues were determined by quantitative real-time RT-PCR (qRT-PCR), using $\beta$-tubulin as the reference gene.

Accumulation levels of CMV-Fny RNAs 2 and 3 were two and four times higher than the corresponding RNAs of CMVLS (Fig. 2), while abundance of CMV-Fny(LS2b) RNAs 2 was reduced by 5 - and 10 -fold, respectively, compared with the corresponding RNA of CMV-LS and CMV-Fny. The accumulation profiles of CMV-Fny RNAs observed in plants harboring CMV-Fny/Tfn-satRNA were very similar to those of CMVFny(LS2b), in the case of RNA 2, and both CMV-Fny(LS2b) and CMV-LS, in the case of RNA 3. The CMV-Fny/TfnsatRNA quantification result was consistent with previous observations which demonstrated a positive correlation between latent infection and viral RNA downregulation (Cillo et al. 2007).

These results suggest that viral RNA accumulation, which is also an indirect indicator for the accumulation of viral proteins in infected tissues, positively correlates with the severity of induced symptoms and is in agreement with the notion that the 3' sequence of CMV RNA 2 cannot be replaced by a homologous region from a different strain without affecting both the accumulation of specific viral RNAs and disease phenotype. The mild phenotype induced by the chimeric strain CMVFny(LS2b) correlated with the mildness of the viral strain from which the RNA $23^{\prime}$ terminus had been cloned, which codes for the $2 \mathrm{~b}$ protein, a viral pathogenicity determinant.

\section{Accumulation levels of miRNA-regulated genes are differentially altered by different inocula in CMV-infected tomato plants.}

We tested whether the accumulation of selected miRNAregulated and non-miRNA-regulated transcripts in tomato could be altered by severe as well as mild CMV strains, and whether the sequence substitution between a severe and mild CMV strain in a region including the $2 b$ open reading frame (ORF), as in CMV-Fny(LS2b), might be sufficient to interchange the strainspecific ability to interfere with miRNA pathway.

The comparison of the expression levels of the gene set from infected and mock-inoculated plants was made by qRTPCR using RNA preparations extracted from leaves at 9 dpi (i.e., before symptom appearance). The abundance of DCL1 and $A G O 1$ transcripts was significantly increased by all the CMV inocula compared with mock-inoculated plants but with evident strain specific differences. For DCL1 mRNA, there was a clear increase in plants infected by CMV-LS (relative quantity $[R Q]>4)$ compared with plants infected by either CMV-Fny or CMV-Fny(LS2b) (RQ between 2.5 and 3) (Fig. $3 \mathrm{~A})$. Conversely, the level of accumulation of $A G O 1$ transcripts was found to be higher in plants infected by CMV-Fny (RQ = 4.9) than in those infected by either CMV-LS or CMVFny(LS2b) (RQ between 3.4 and 4) (Fig. 3A).

Two of five TF transcripts, $A R F 8$ and TCP3, did not show overaccumulation upon virus infection regardless of the inoculated strain. The two inocula containing the CMV-LS RNA 2 $3^{\prime}$ sequence induced a clear increase in the transcript levels of $N A C l$ (RQ > 7) whereas, in samples infected with CMV-Fny, the abundance of NACl was only double that of mock-inoculated plants. $H D-Z I P$ and $T C P 4$ were increased in plants infected with CMV-Fny to levels of approximately $R Q=2$, while CMV-LS caused only a limited increase of HD-ZIP accumulation and CMV-Fny(LS2b) did not result in higher accumulation of the two transcripts (Fig 3A).

We included in the analysis the quantification of the Argonaute-like gene AGO4 and another TF, PHAN, which have not been associated thus far with miRNA-guided expression regulation. Although there was no statistical difference between AGO4 expression in mock- or virus-inoculated plants, mean abundance of its transcripts in CMV-LS was almost double that in CMV-Fny infected samples, a difference determined by weak upregulation in the former and downregulation in the latter case. The PHAN mRNA accumulation levels in plants infected by CMV-Fny were four times higher than in mockinoculated plants, while the other inocula did not cause any alteration of PHAN transcripts (Fig. 3B).

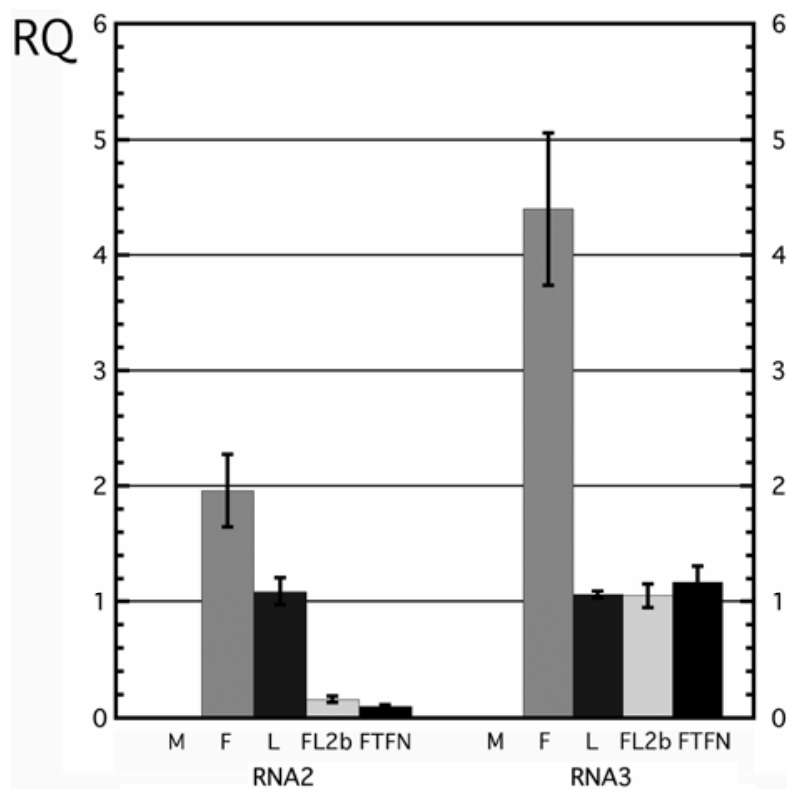

Fig. 2. Accumulation levels of Cucumber mosaic virus (CMV) RNAs 2 and 3 in tomato leaves 9 days postinoculation (dpi) with four CMV inocula, determined by quantitative real-time reverse-transcription polymerase chain reaction analysis. According to the comparative method (relative quantity $\left.[\mathrm{RQ}]=2^{-\Delta \Delta \mathrm{Ct}}\right)$, cycle threshold $(\mathrm{Ct})$ values of the target viral RNA were first normalized to the expression levels of $\beta$-tubulin mRNA (reference gene), and then made relative to the amount of the target viral RNA in an individual CMV-LS-infected (L) sample, representing the calibrator. For the calibrator, $-\Delta \Delta \mathrm{Ct}=0$ and $\mathrm{RQ}=1$ and, for the remaining samples, the value of RQ indicates the fold change of viral RNA accumulation relative to the calibrator. Columns represent mean values from three biological replicates and vertical bars indicate standard errors. M, mock-inoculated plants; F, CMV-Fny; L, CMV-LS; FL2b, CMV-Fny(LS2b); FTFN, CMVFny/Tfn-satRNA. 
Altogether, these results indicate that, in tomato leaf tissues, CMV strains are able to interfere differentially with the accumulation of transcripts of the selected genes and that differences in the 3 '-terminal region of RNA 2 may account for different mRNA accumulation. For example, whereas some genes were upregulated only (TCP4 and PHAN) or to higher amounts ( $A G O 1$ and $H D-Z I P)$ in the presence of CMV-Fny, there was a marked overregulation for $N A C l$ in plants infected by the two strains having the RNA $23^{\prime}$ region derived from CMV-LS.

\section{Accumulation levels of miRNA and miRNA*} are differentially altered in CMV-infected tomato plants.

The interference of viral infection with miRNA pathways in tomato, predicted by the observed stable accumulation of some mRNAs that are target of miRNA-guided cleavage, was further investigated by qRT-PCR quantification of the involved miRNAs and miRNA*s. Tomato leaves infected by CMV-Fny showed a significant level of accumulation of DCL1 (Fig. 3) and a parallel stabilization of miR162 and, in particular, of miR162* (Fig. 4), while the infection of CMV-LS and CMVFny(LS2b) did not induce the accumulation of these miRNA species despite the observed increase of DCL1 transcript (Fig. 3). MiR168 and miR168* showed accumulation levels with the same strain-specific variation trend of mRNA target $A G O 1$ (Fig. 3), although the differences in miR168 values were not statistically significant, probably because of the high variability observed among biological replicates (Fig. 4).

MiR164 and miR164* accumulation levels reflected those of $N A C 1$, with the only difference for CMV-LS that stabilized the accumulation of miR164* so that it was more abundant than in tomato leaves infected by CMV-Fny(LS2b) (Fig. 4).
Also miR165, miR319, and their star strands showed accumulation levels varying with the same tendency of their target genes (HD-ZIP and TCP4, respectively), with higher values due to CMV-Fny infection and no or very limited variations induced by the other CMV strains compared with mock-inoculated plants (Fig. 4). Finally, miR167, which targets $A R F 8$ for degradation, did not show any variation of accumulation levels, thus confirming that CMV infections do not alter the expression levels of this gene (Fig. 4).

These results indicated that, with some exceptions as in the notable case of $D C L 1 / \mathrm{miR} 162$, there is a substantial correlation between the accumulation levels of target mRNAs and the corresponding miRNA species, consistent with the proposed mechanism by which infection of mild and severe CMV strains would differentially perturb miRNA-guided regulation of gene expression.

\section{Minor modifications of miRNA accumulation and gene expression regulation \\ in symptomless CMV/satRNA-infected plants.}

Having shown that CMV infections induced modifications of miRNA pathways for the regulation of different classes of genes, we addressed the question of whether asymptomatic infections deriving from the inoculation of CMV-Fny in the presence of the ameliorative Tfn-satRNA might be associated with some modifications on miRNA-guided regulation of the genes selected for this study.

Results of these experiments are shown in Figure 5. In agreement with what was shown previously, all analyzed transcripts, except for $A R F 8$ and TCP3, were upregulated upon infection with CMV-Fny, reaching RQ levels comparable with what was shown in Figure 3. CMV-Fny/Tfn-satRNA infec-
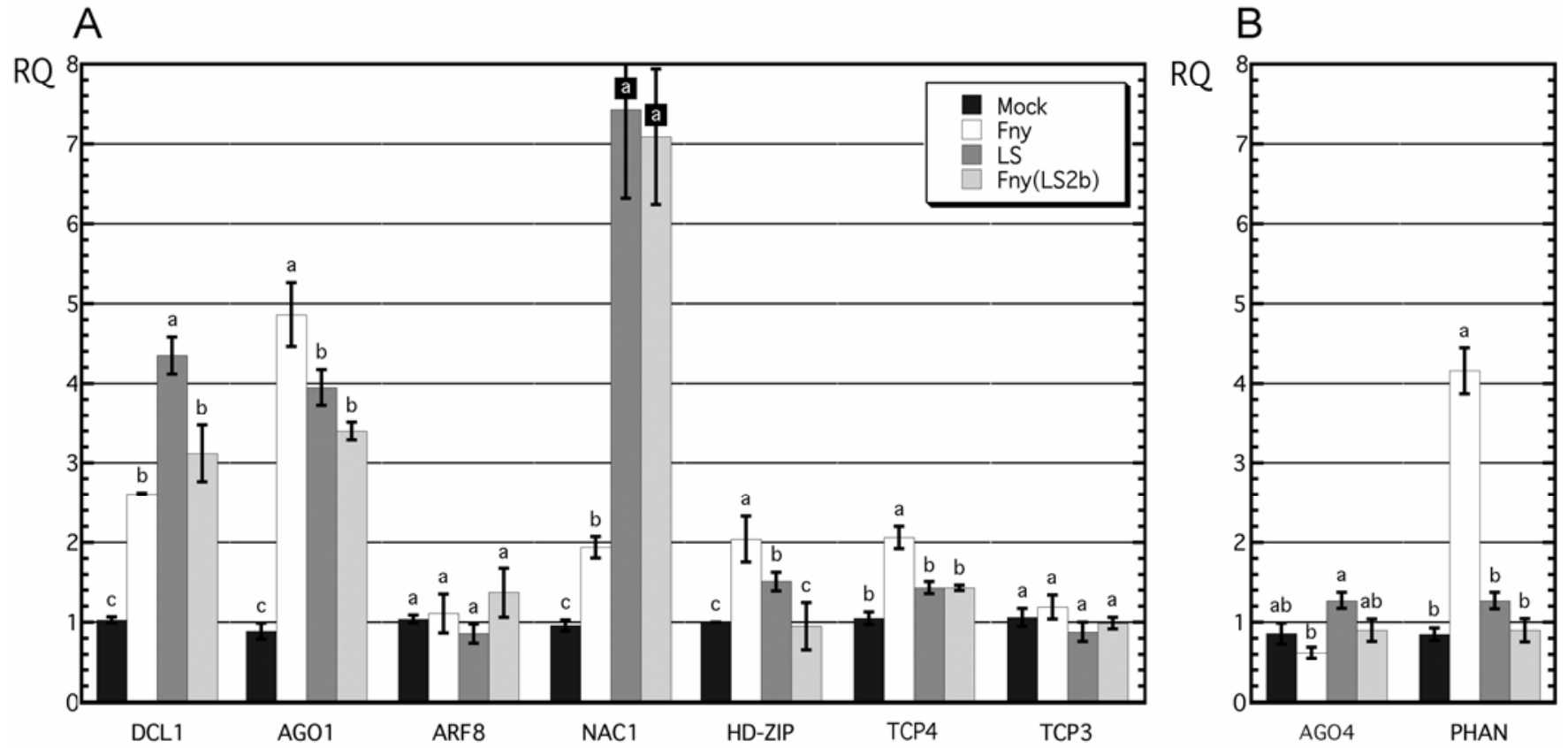

Fig. 3. Expression levels of nine genes modulated by viral infection in tomato plants 9 days postinoculation (dpi) with Cucumber mosaic virus (CMV). Relative quantities (RQs) of A, seven microRNA (miRNA)-regulated transcripts: Dicer-like 1 (DCL1), Argonaute 1 (AGO1), ARF8, NACl, HD-ZIP, TCP4, and TCP3; and B, two non-miRNA-regulated transcripts: Argonaute 4 (AGO4) and AS1/PHANTASTICA (PHAN) determined by quantitative real-time reversetranscription polymerase chain reaction analysis. Total RNA samples were extracted at 9 dpi with three different CMV strains or from mock-inoculated plants as the negative controls, as indicated by the gray-scale color legend. According to the comparative method $\left(\mathrm{RQ}=2^{-\Delta \Delta C t}\right)$, cycle threshold $(\mathrm{Ct})$ values of the target transcripts were first normalized to the expression levels of $\beta$-tubulin mRNA (reference gene) and then made relative to the amount of the target mRNA in an individual noninfected (mock-inoculated) sample, representing the calibrator. For the calibrator, $-\Delta \Delta \mathrm{Ct}=0$ and $\mathrm{RQ}=1$ and, for the remaining samples, the value of RQ indicates the fold change of gene expression relative to the calibrator. Columns represent mean RQ values from three biological replicates and vertical bars indicate standard errors. Statistical significance of expression differences of individual genes upon infection by different CMV strains was analyzed with one-way analysis of variance. Differences were assumed to be statistically significant, and indicated with different letters, for $P<$ 0.05 (Tukey post-hoc test). 
tions, on the contrary, did not cause stabilization of miRNAregulated transcripts, with the important exception of the NAC1 mRNA, for which accumulation levels were approximately sevenfold higher than mock-inoculated plants and double than CMV-Fny-infected plants (Fig. 5A). CMV-Fny, in the absence and, more evidently, in the presence of Tfn-satRNA, reduced the accumulation of $\mathrm{AGO} 4$ transcripts (Fig. 5B). On the other hand, PHAN mRNA abundance increased in CMVFny-infected plants but did not change expression levels upon CMV-Fny/Tfn-satRNA infection (Fig. 5B).

Also in this case, mRNA accumulation correlated with CMV-Fny-induced stabilization of the respective miRNA and miRNA* (Fig. 6). However, compared with the results shown in Figure 4, in this second set of qRT-PCR experiments, miR164* levels, unlike miR164, were not different from those recorded in healthy plants. With CMV-Fny/Tfn-satRNA, the abundance of the selected miRNA was substantially similar to that of healthy controls, with the exception of miR168* and miR165*, whose accumulation levels were increased (Fig. 6).

These data, which confirmed the positive correlation between accumulation levels of miRNAs and their target transcripts in virus-infected tomato plants, support the original hypothesis of minimal perturbation of gene expression in symptomless CMV/satRNA infections.

\section{Interference with host gene expression and miRNA accumulation is not active in CMV-inoculated tomato leaves.}

All the data presented above refer to analyses on RNA extracted from systemically infected leaf tissues at 9 dpi. We also monitored the abundance of the selected library of mRNAs and miRNAs in cotyledons 2 dpi with CMV-LS and CMV-Fny. The results of these experiments, reported in Table 1, showed that, at an early stage of infection, neither CMV-Fny nor
CMV-LS induced significant expression variations in any of the six transcripts analyzed by qRT-PCR. The accumulation levels at 2 dpi were also tested for two miRNAs, miR168 and miR164, and, in both cases, the abundance in healthy plants did not differ from that measured in CMV-infected tomato plants. These results indicate that disruption of miRNA pathways is not an early effect of CMV infection on tomato and that the deriving accumulation of mRNAs and miRNAs is evident in systemically infected but not in directly inoculated leaf tissues.

\section{DISCUSSION}

In this study, we have shown that, in tomato, some pathogenic properties of two different CMV strains are affected by the 3 '-terminal portion of RNA 2, a region including the $2 b$ ORF, and correlate to some extent with the alteration of miRNA metabolism.

In A. thaliana, CMV-Fny symptoms are particularly severe compared with those induced by CMV-LS, and the effect has been attributed to the differential ability of the $2 \mathrm{~b}$ protein of mild (CMV-LS) and severe (CMV-Fny) strains to interfere with miRNA metabolism (Lewsey et al. 2007). We have shown that, in tomato, three $\mathrm{TF}$ with a known role in leaf morphogenesis, $T C P 4, H D-Z I P$, and PHAN, were upregulated specifically by CMV-Fny infections. The lanceolate mutation in tomato revealed the role of the related gene, a homolog of the A. thaliana TCP4 TF, in the proper development and shaping of compound leaves (Ori et al. 2007). Both HD-ZIP, coding for a homeodomain-leucine zipper DNA-binding protein homologous to the $A$. thaliana TF PHAVOLUTA and PHABULOSA, and PHAN, the ortholog of A. thaliana MYB ASYMMETRIC LEAVES1 (AS1), are important for establishing the adaxial cell fate during leaf dorso-ventral patterning (Chitwood et al. 2007; Willmann and

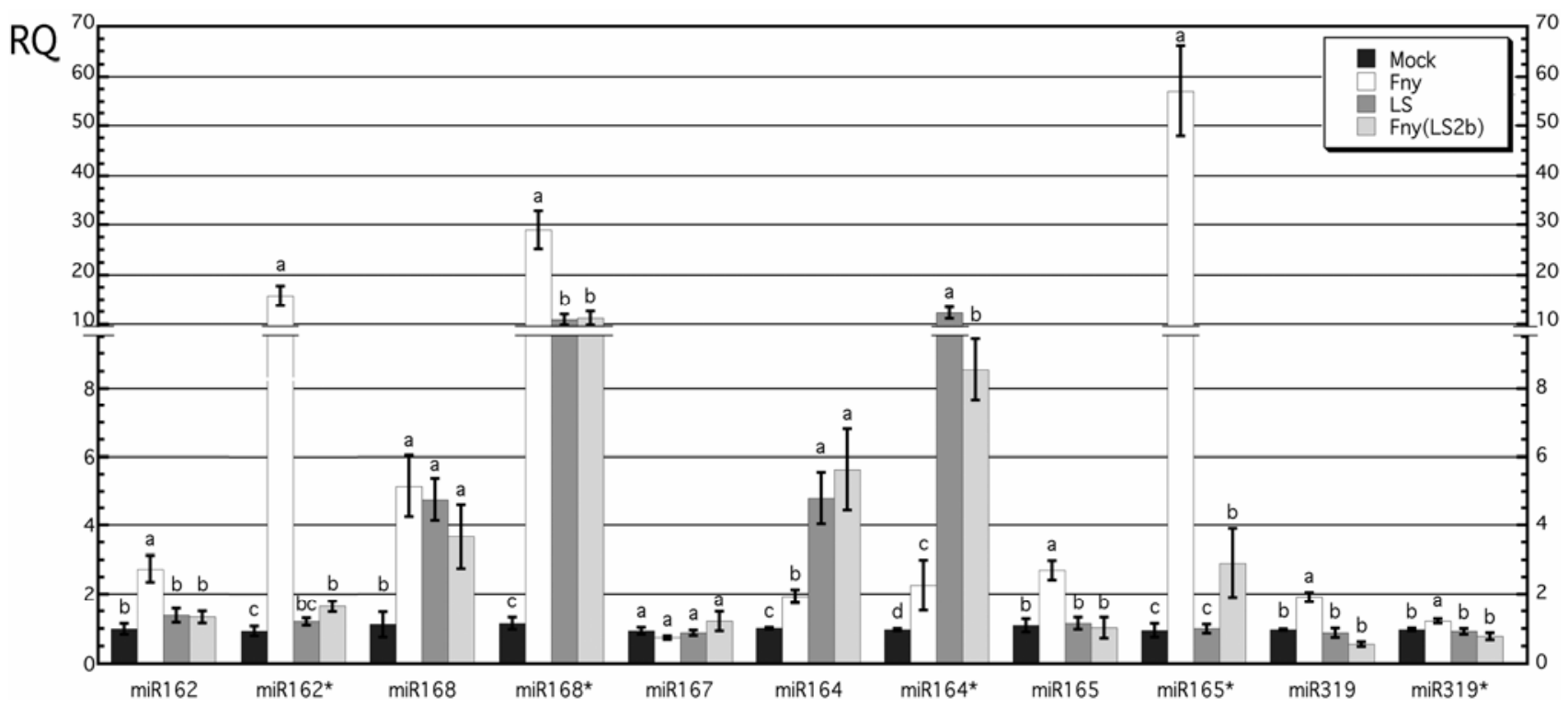

Fig. 4. Expression levels of selected microRNA (miR) and microRNA* (miR*) modulated by viral infection in tomato plants 9 days postinoculation (dpi) with Cucumber mosaic virus (CMV). Relative quantities (RQs) were determined by quantitative real-time reverse-transcription polymerase chain reaction analysis. Total RNA samples were extracted at 9 dpi with three different CMV strains, or from mock-inoculated plants as the negative controls, as indicated by the gray-scale color legend. According to the comparative method $\left(\mathrm{RQ}=2^{-\Delta \Delta \mathrm{Ct}}\right)$, cycle threshold $(\mathrm{Ct})$ values of the target microRNA were first normalized to the expression levels of glyceraldehyde 3-phosphate dehydrogenase (GAPDH) mitochondrial (m)RNA (reference gene), and then made relative to the amount of the target microRNA in an individual noninfected (mock-inoculated) sample, representing the calibrator. According to the comparative method $\left(\mathrm{RQ}=2^{-\Delta \Delta \mathrm{Ct}}\right)$, cycle threshold $(\mathrm{Ct})$ values of the target transcripts were first normalized to the expression levels of GAPDH mRNA (reference gene) and then made relative to the amount of the target miRNA in an individual noninfected (mock-inoculated) sample, representing the calibrator. For the calibrator, $\Delta \Delta \mathrm{Ct}=0$ and $\mathrm{RQ}=1$ and, for the remaining samples, the value of RQ indicates the fold change of miRNA expression relative to the calibrator. Columns represent mean RQ values from three biological replicates and vertical bars indicate standard errors. Statistical significance of expression differences of individual genes upon infection by different CMV strains was analyzed with one-way analysis of variance. Differences were assumed to be statistically significant, and indicated with different letters, for $P<0.05$ (Tukey post-hoc test). 
Poethig 2007). Strict spatial and temporal transcriptional control of TCP4 and HD-ZIP by miR319 and miR165/166, respectively, are indispensable for correct leaf development (Garcia 2008), which explains why mutations of $A G O 1$, generating dysfunctional miRNA processing and enhanced accumulation of these and other TF transcripts in the absence of miRNA-guided mRNA cleavage, show defects in lateral organ polarity and leaf and flower morphology (Kidner and Martienssen 2004; Vaucheret et al. 2004). In this scenario, it is not surprising that the alteration of miRNA-regulated expression of $A G O 1, T C P 4$, and $H D$-ZIP by CMV-Fny in infected tomato plants led to a strong phenotype displaying leaf-altered morphology. A causal correlation between virus-induced perturbation of miRNA pathways and disease symptoms has already been suggested by several authors (Kasschau et al. 2003; Zhang et al. 2006; Bazzini et al. 2007; Shiboleth et al. 2007). Our work shows that, in tomato, genes such as PHAN, whose expression is not, according to present knowledge, directly regulated by miRNA, are also abnormally expressed and are likely to play an important part in generating the observed disease phenotype. We can hypothesize that primary events due to blocked miRNA activity and abnormal TF accumulation may lead to a secondary cascade of events involving other genes important in leaf morphogenesis. Nevertheless, a second hypothesis could implicate a direct participation of PHAN in the host response to CMV infection. In fact, the activation or repression of $A S 1$ or $P H A N$ genes in response to viroidal, fungal, and bacterial pathogens has been described in different plants (Martin et al. 2007; Nurmberg et al. 2007). The disease phenotype of CMV-LS on tomato was milder than that induced by CMV-Fny, a trait also reported on different hosts such as tobacco and cucurbits (Zhang et al. 1994; Wang et al. 2002), and correlated with the observation that CMV-LS $2 b$ protein did not interfere with miRNA-regulated gene expression (Lewsey et al. 2007). The results of our work also support this hypothesis in that TF required for leaf morphogenesis (HD-ZIP, TCP genes, and related miRNA/miRNA* as well as $P H A N$ ) showed unaltered or slightly altered expression upon CMV-LS inoculation. However, in the light of our results, that show that the expression of genes other than the mentioned TF is indeed markedly altered by CMV-LS infection (discussed below), it would be more appropriate to conclude that the two CMV strains induce different symptoms in tomato because of their ability to differently interfere with the miRNA-guided expression of some genes. CMV-Fny(LS2b) was a useful tool for addressing the question on whether, in CMV infections, the $2 \mathrm{~b}$ protein was the viral factor eliciting modifications of miRNA-regulated gene expression, as supported by studies on transgenic plants expressing the $2 \mathrm{~b}$ protein (Zhang et al. 2006; Lewsey et al. 2007). This hypothesis seems to be supported by the coincidence of gene and miRNA expression data in samples inoculated with CMVLS and CMV-Fny(LS2b) that exhibited a similar phenotype and significantly differed from CMV-Fny despite the fact that, out of
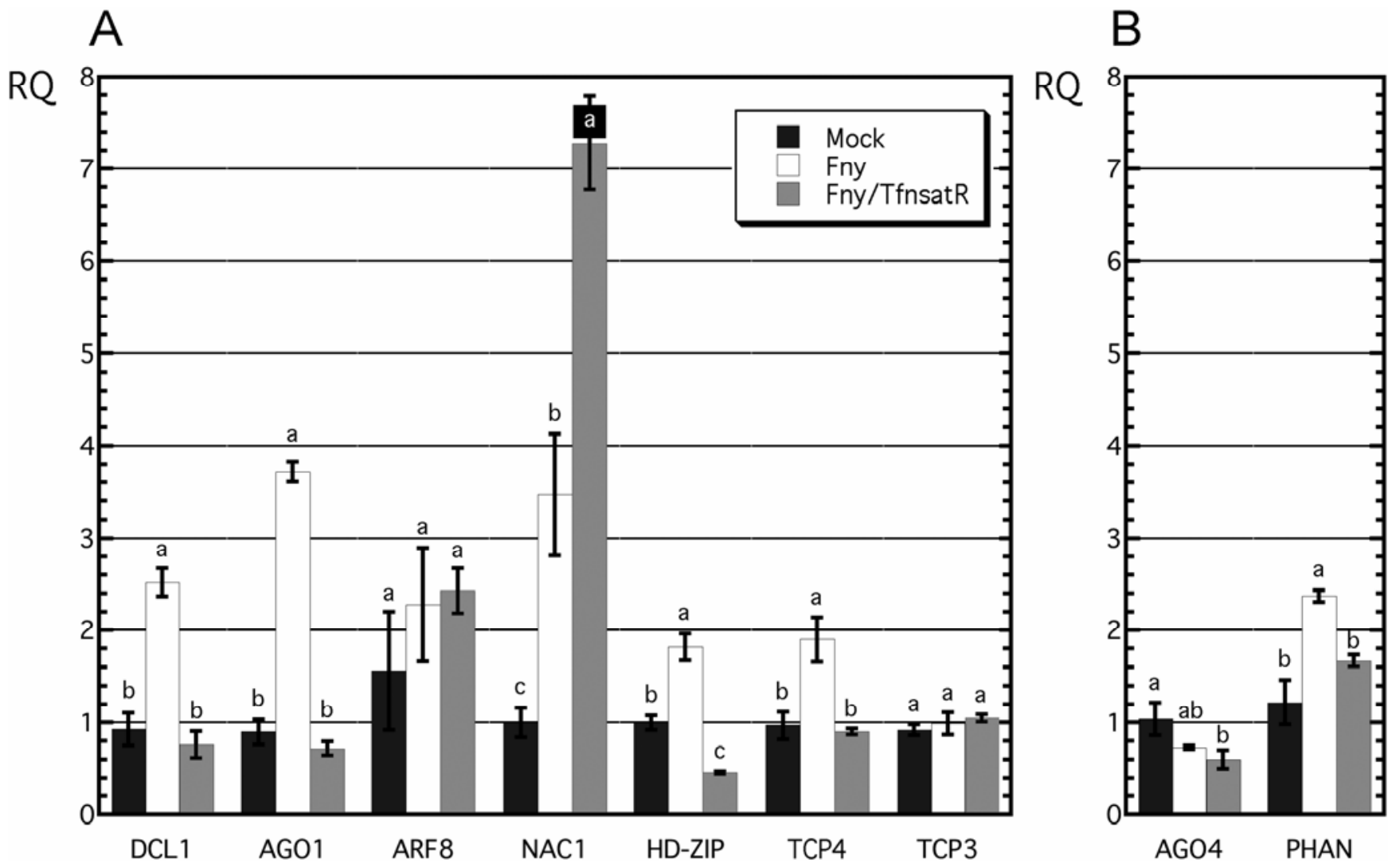

Fig. 5. Expression levels of nine genes modulated by viral infection in tomato plants 9 days postinoculation (dpi) with Cucumber mosaic virus (CMV). Relative quantities (RQs) of A, seven microRNA (miRNA)-regulated transcripts: Dicer-like 1 (DCL1), Argonaute 1 (AGO1), ARF8, NAC1, HD-ZIP, TCP4, and TCP3; and B, two non-miRNA-regulated transcripts: Argonaute 4 (AGO4) and AS1/PHANTASTICA (PHAN) determined by quantitative real-time reverse-transcription polymerase chain reaction analysis. Total RNA samples were extracted at 9 dpi with CMV-Fny (Fny, white columns) or CMV-Fny/TfnsatRNA (Fny/TfnsatR, light-gray columns), or from mock-inoculated plants (dark-gray columns) as the negative controls. According to the comparative method $\left(\mathrm{RQ}=2^{-\Delta \Delta \mathrm{Ct}}\right)$, cycle threshold $(\mathrm{Ct})$ values of the target transcripts were first normalized to the expression levels of $\beta$-tubulin mRNA (reference gene) and then made relative to the amount of the target mRNA in an individual noninfected (mock-inoculated) sample, representing the calibrator. For the calibrator, $-\Delta \Delta \mathrm{Ct}=0$ and $\mathrm{RQ}=1$ and, for the remaining samples, the value of RQ indicates the fold change of gene expression relative to the calibrator. Columns represent mean RQ values from three biological replicates and vertical bars indicate standard errors. Statistical significance of expression differences of individual genes upon infection by different CMV strains was analyzed with one-way analysis of variance. Differences were assumed to be statistically significant, and indicated with different letters, for $P<0.05$ (Tukey post-hoc test). 
the $3^{\prime}$ fragment of RNA 2, the recombinant strain CMV-Fny (LS2b) shared the rest of the genome with CMV-Fny. However, the chimeric CMV-Fny(LS2b) RNA 2 does not permit isolation of the $2 \mathrm{~b}$ functions from those of the RNA $23^{\prime}$ untranslated region and the $2 a / 2 b$ overlapping region, whose possible role in specific pathogenic processes has been recently discussed (Du et al. 2008).

The ability of CMV-Fny to induce severe symptoms in tomato plants was dramatically affected by the coinoculation of TfnsatRNA, which gave rise to symptomless infections. Our work demonstrates unaltered expression of the selected miRNAs and their target genes, associated with a substantial downregulation of CMV RNA 2 upon Tfn-satRNA coinfection, to levels that were much lower than those detected in infections with CMVFny and other symptomatic CMV/satRNA combinations (Fig. 2) (Cillo et al. 2007). Thus, we propose that low levels of RNA 2 in the presence of Tfn-satRNA would probably imply the translation of reduced amounts of $2 b$ and, consequently, the reduced ability to interfere with $A G O 1$ activity and miRNA-mediated gene expression. Therefore, this work provides the first direct evidence that the differential alteration of miRNA pathway for the regulation of gene expression could contribute to elucidating the mechanisms underlying symptom suppression co-determined by certain satRNAs in CMV-infected plants.

In previous studies, the analysis of CMV effects on the miRNA pathway was mainly limited to the expression of $2 b$ proteins belonging to different strains, which led to the conclusion that subgroup I (e.g., CMV-Fny) 2b but not subgroup II (e.g., CMV-LS, CMV-Q) 2b proteins were able to block AGO1 activity and impair proper miRNA-guided mRNA cleavage in A. thaliana (Chapman et al. 2004; Zhang et al. 2006; Lewsey et al. 2007). Our study, on the other hand, explored the effects on miRNA pathways of authentic CMV infections on tomato, and produced some original results on the alteration of $D C L 1$, $A G O 1, A G O 4$, and $N A C 1$ expression levels that could be due to changes in both experimental strategy and host plant system. According to Zhang and associates (2006), CMV-Fny 2b, unlike CMV-Q 2b, is able to stabilize to high levels DCL1 and miR162/miR162* accumulation. In CMV-infected tomato plants, we showed that (i) DCL1 mRNA levels did not always correlate with miR162 amounts, both of which accumulated to higher levels than healthy plants only in the case of CMV-Fny infection; and (ii) DCL1 modulation was significantly different between CMV-LS and CMV-Fny(LS2b), with the former inducing higher transcript levels than the latter despite the fact that the abundance of the respective miRNAs was not different from that of healthy plants. Thus, the two strains sharing the $3^{\prime}$

Table 1. Expression levels of microRNA (miRNA)-regulated transcripts and relative miRNAs at 2 days postinoculation in Cucumber mosaic virus (CMV)-Fny- and CMV-LS-infected tomato plants, determined by quantitative real-time reverse-transcriptioin polymerase chain reaction and expressed as relative quantity $(\mathrm{RQ})^{\mathrm{a}}$

\begin{tabular}{lccc}
\hline Gene/miRNA & Mock & Fny & LS \\
\hline DCL1 & $1.00 \pm 0.10$ & $0.78 \pm 0.09$ & $0.72 \pm 0.09$ \\
miR162 & nd & nd & nd \\
$A G O 1$ & $0.92 \pm 0.05$ & $0.80 \pm 0.04$ & $0.72 \pm 0.08$ \\
miR168 & $1.14 \pm 0.16$ & $1.18 \pm 0.26$ & $1.28 \pm 0.09$ \\
NAC1 & $1.07 \pm 0.15$ & $1.08 \pm 0.04$ & $1.02 \pm 0.19$ \\
miR164 & $1.13 \pm 0.06$ & $1.16 \pm 0.14$ & $1.18 \pm 0.06$ \\
HD-ZIP & $1.17 \pm 0.08$ & $1.25 \pm 0.05$ & $0.93 \pm 0.09$ \\
miR165 & nd & nd & nd \\
TCP4 & $1.33 \pm 0.16$ & $1.19 \pm 0.12$ & $1.02 \pm 0.13$ \\
miR319 & nd & nd & nd \\
PHAN & $1.03 \pm 0.02$ & $0.99 \pm 0.05$ & $0.95 \pm 0.08$ \\
\hline
\end{tabular}

${ }^{a}$ Values were first normalized to the expression levels of $\beta$-tubulin (mRNA quantification) or glyceraldehyde 3-phosphate dehydrogenase (miRNA quantification) and then made relative to the amount of the target mRNA or miRNA in noninfected (mock-inoculated) plants. Data represent RQ mean values from three biological replicates \pm standard errors; nd $=$ not determined.

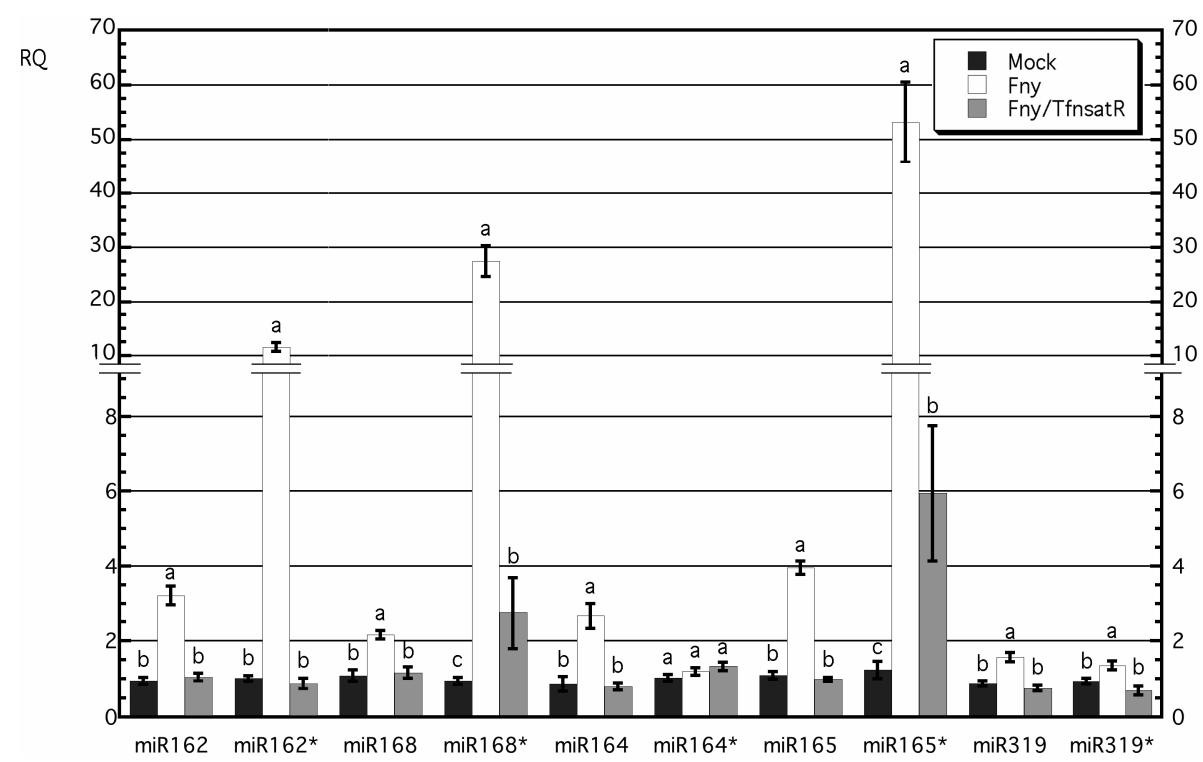

Fig. 6. Expression levels of selected microRNA (miR) and microRNA* (miR*) modulated by viral infection in tomato plants 9 days postinoculation (dpi) with Cucumber mosaic virus (CMV). Relative quantities (RQs) were determined by quantitative real-time reverse-transcription polymerase chain reaction analysis. Total RNA samples were extracted at 9 dpi with CMV-Fny or CMV-Fny/Tfn-satRNA, or from mock-inoculated plants as the negative controls. Cycle threshold $(\mathrm{Ct})$ values of the target microRNA (miRNA) were first normalized to the expression levels of glyceraldehyde 3-phosphate dehydrogenase (GAPDH) mitochondrial (m)RNA (reference gene), and then made relative to the amount of the target miRNA in an individual noninfected (mockinoculated) sample. According to the comparative method ( $\left.\mathrm{RQ}=2^{-\Delta \Delta \mathrm{Ct}}\right)$, cycle threshold $(\mathrm{Ct})$ values of the target transcripts were first normalized to the expression levels of GAPDH mRNA (reference gene) and then made relative to the amount of the target miRNA in an individual noninfected (mockinoculated) sample, representing the calibrator. For the calibrator, $-\Delta \Delta \mathrm{Ct}=0$ and $\mathrm{RQ}=1$ and, for the remaining samples, the value of $\mathrm{RQ}$ indicates the fold change of miRNA expression relative to the calibrator. Columns represent mean RQ values from three biological replicates and vertical bars indicate standard errors. Statistical significance of expression differences of individual genes upon infection by different CMV strains was analyzed with one-way analysis of variance. Differences were assumed to be statistically significant, and indicated with different letters, for $P<0.05$ (Tukey post-hoc test). 
terminus of the CMV-LS RNA 2 and its $2 \mathrm{~b}$ might alter DCL1 accumulation levels via additional, $2 \mathrm{~b}$ - or miRNA-independent regulation mechanisms that could be promoted by CMV-LS and, to a lesser extent, also by CMV-Fny(LS2b) (Fig. 3).We showed that CMV-Fny infections were able to induce overaccumulation of $A G O 1$ and miR168/miR168* in infected tomato plants, similarly to what was evidenced in Arabidopsis plants infected with the same CMV strain or constitutively expressing CMV-Fny 2b (Zhang et al. 2006). In our experiments, CMVLS and CMV-Fny(LS2b) also elicited the accumulation of $A G O 1$ and miR168/miR168*, denoting a remarkable difference with CMV-Q 2b-transgenic A. thaliana plants (Zhang et al. 2006). This result could be an indication of a higher responsiveness of AGO1 miRNA-regulated expression to actual viral infections compared with transgenic expression of individual viral proteins, as also was shown on different virus-host models (Shiboleth et al. 2007).

We also looked at the accumulation levels of $A G O 4$, another member of the Argonaute gene family that is not believed to be controlled by the miRNA pathway. This was the only gene among the selected set whose abundance was weakly downregulated by CMV-Fny infection to accumulation levels that were significantly lower than those recorded in the course of CMV-LS infections. Therefore, our results are in agreement with evidence suggesting that some CMV $2 b$ silencing suppression functions, mediated by either transcriptional suppression of AGO4 (Ye et al. 2009) or by a direct 2b-AGO4 interaction at the protein level (Tomas Canto, personal communication), may counteract plant RNA-based defense mechanisms by interfering with AGO4-dependent RNA-directed DNA methylation activity and systemic RNA silencing (Jones et al. 2006).

A peculiar pattern of expression emerged by analyzing $N A C l$ transcripts in infected tomato plants. Numerous members of the NAC family of TF has been shown to be responsive to both biotic and abiotic stresses (Olsen et al. 2005), and specific NAC genes of solanaceous species are transcriptionally activated following infections by viral or fungal pathogens (Collinge and Boller 2001; Oh et al. 2005; Selth et al. 2005). However, the originality of our findings resides in the miRNAmediated upregulation of $N A C 1$ transcripts in infections characterized by a mild or symptomless disease phenotype (i.e., with CMV mild strains or in the presence of a benign satRNA). Because CMV-LS $2 \mathrm{~b}$ expression in transgenic Arabidopsis plant did not affect $N A C 1$ and miR164 accumulation levels in either leaf or root tissues (Lewsey et al. 2007), it is tempting to speculate that the CMV-LS $2 \mathrm{~b}$ protein could trigger an altered NAC1 miRNA-guided regulation in tomato but not in Arabidopsis. On the other hand, because NACl overaccumulation also occurred in plants infected by CMV-Fny/Tfn-satRNA and, in this case, the mechanism of upregulation appears to be nonmiRNA mediated, it seems possible that other viral factors can affect levels of NACl accumulation through different mechanisms, as has been demonstrated in tomato plants infected with Tomato leaf curl virus (Selth et al. 2005). It would be very interesting to further investigate whether NAC1-enhanced expression may play a direct role in plant defense against CMV infections in tomato.

The alteration of miRNA pathways, as described above, was observed at 9 dpi in systemically infected leaf tissues but not at 2 dpi on directly inoculated leaves. It is possible that, at earlier time points, the disturbing interaction between viral infection and the miRNA-dependent gene regulation activity is not yet detectable in terms of altered mRNA and miRNA accumulation levels. Nevertheless, a microarray analysis showed that a massive alteration of gene expression profiles is clearly present at $2 \mathrm{dpi}$, with over 1,000 differentially expressed genes already detectable in CMV-Fny-infected tomato plants (F. Cillo, A.
Polverari, and D. Gallitelli, unpublished data). The mechanisms by which the $2 \mathrm{~b}$ protein has been shown to suppress RNA silencing, targeting initiation of the process at the growing points of the plants (Brigneti et al. 1998), might explain the absence of effects on miRNA pathways in developed, inoculated tissues.

In conclusion, this study provides evidence, as also shown by a very recent article (Feng et al. 2009), of the existence of virusinduced and miRNA-mediated pathogenic processes in infected tomato plants. Moreover, we show that fundamental similarities but also remarkable differences arise from comparing interaction mechanisms of viral pathogens with model plants, such as $A$. thaliana, versus important crop plants like tomato. Further work is needed to clarify the role of these host-specific but also strain-specific differences in the onset of susceptible or tolerant response of the host to viral infection, and to understand whether the new information may be exploited to introduce new strategies for crop protection from viruses.

\section{MATERIALS AND METHODS}

\section{Recombinant plasmid construct.}

A recombinant CMV RNA 2 clone has been obtained, in which the original 3 '-terminal sequence of CMV-Fny, including the whole $2 \mathrm{~b}$ protein coding sequence, has been replaced by the corresponding region of CMV-LS.

Plasmid pFny209 (Rizzo and Palukaitis 1990), carrying the cDNA for CMV-Fny RNA 2, was mutagenized in order to introduce a SacII restriction site. Changes applied to pFny209 were T2297G and A2298G, using the PCR-based protocol of the QuickChange XL Site-Directed Mutagenesis Kit (Stratagene, La Jolla, CA, U.S.A.), and the mutagenized clone was named pFny209_SacII. The thermal cycles for PCR were as follows: initial denaturation at $95^{\circ} \mathrm{C}$ for $30 \mathrm{~s} ; 12$ cycles at $95^{\circ} \mathrm{C}$ for $30 \mathrm{~s}, 55^{\circ} \mathrm{C}$ for $1 \mathrm{~min}$, and $68^{\circ} \mathrm{C}$ for $6 \mathrm{~min}$. At the same time, a DNA fragment equivalent to the $3^{\prime}$-terminal region (nucleotides 2,294 to 3,038) of CMV-LS RNA 2 was amplified from pLS-CMV2, the vector carrying the corresponding cDNA (Zhang et al. 1994), using AccuPrime Taq DNA Polymerase High Fidelity (Invitrogen, Paisley, U.K.). The primers for this amplification were designed in order to introduce SacII and PstI restriction sites at the 5' and 3' ends of the fragment, respectively. The PCR product was first cloned into a pGEM-T vector (Promega Corp., Madison, WI, U.S.A.), then introduced by T4 DNA ligase (Promega Corp.) in pFny209_SacII previously digested with SacII and PstI restriction endonucleases. All fragments obtained during the cloning procedure and the final vector pFny209(LS2b) were confirmed by sequencing before use.

\section{Plants and viruses.}

Seedlings of tomato (Solanum lycopersicum cv. UC82) were grown in glasshouse with controlled temperature at $22^{\circ} \mathrm{C}$ $\left( \pm 2^{\circ} \mathrm{C}\right)$ with a 16 -h photoperiod.

The two strains CMV-Fny (Owen and Palukaitis 1988) and CMV-LS (Wahyuni et al. 1992), received from P. Palukaitis (SCRI, Dundee, U.K.), were maintained on UC82 tomato and purified from systemically infected leaves, collected 12 days after inoculation, according to Lot and associates (1972).

The recombinant strain CMV-Fny(LS2b) was obtained by in vitro transcription of the following three CMV genomic RNAs: CMV-Fny RNA 1 and RNA 3, transcribed from the vectors pFny109 and pFny309, respectively (Rizzo and Palukaitis 1990), and the chimeric RNA 2, transcribed from the vector pFny209(LS2b), described in the previous paragraph. The mechanical coinoculation of the three transcribed RNAs resulted in systemic infection of tomato plants, from which the 
strain was purified as indicated above. The inoculum combining CMV-Fny plus the CMV-Tfn-satRNA was obtained by coinoculation of the corresponding in vitro transcripts, according to published methods (Cillo et al. 2004).

Inoculation of test plants was carried out mechanically at the cotyledon stage with sap from systemically infected tomato leaf tissues at 12 to 15 dpi homogenized in 20 volumes of 100 $\mathrm{mM}$ phosphate buffer, $\mathrm{pH}$ 7.2.
RNA extraction and qRT-PCR analysis.

Total RNA was extracted either from CMV-inoculated or mock-inoculated cotyledon leaf tissues of tomato plants $2 \mathrm{dpi}$, or from systemically infected second true leaves 9 dpi, using TRIzol reagent (Invitrogen). RNA preparations were subjected to on-column DNase digestion (RNase-free DNase set and RNeasy mini kit; Qiagen, Hilden, Germany), denatured at $95^{\circ} \mathrm{C}$ for 3 $\mathrm{min}$, and reverse-transcribed in the presence of random hexam-

Table 2. List of genes and microRNAs (miRNAs) and primer sequences for quantitative real-time reverse-transcription polymerase chain reaction analysis

\begin{tabular}{|c|c|c|c|c|c|c|c|c|}
\hline Gene & Gene name & Protein function & $\begin{array}{l}\text { Biological } \\
\text { process }\end{array}$ & Accession & Primer sequence $^{a}$ & $\begin{array}{l}\text { Related } \\
\text { miRNA }\end{array}$ & $\begin{array}{l}\text { Primer } \\
\text { name }^{b}\end{array}$ & $\begin{array}{c}\text { Primer } \\
\text { sequence }^{c}\end{array}$ \\
\hline \multirow[t]{2}{*}{$D C L 1$} & DICER-LIKE 1 & Ribonuclease III & RNA silencing & BI209312 & for actgtatcgatgtgtgcacgag & $\operatorname{miR} 162$ & sly-miR162 & $\begin{array}{l}\text { for cgccgctcgataaac } \\
\text { ctctgcat }\end{array}$ \\
\hline & & & & & $\begin{array}{l}\text { rev gagttccaatagaagagctg } \\
\text { ctg }\end{array}$ & & sly-miR $162 *$ & $\begin{array}{l}\text { for cgecgcggaggca } \\
\text { gcggtaccat }\end{array}$ \\
\hline \multirow[t]{2}{*}{$A G O 1$} & ARGONAUTE 1 & Ribonuclease $\mathrm{H}$ & RNA silencing & BP901659 & $\begin{array}{l}\text { for ggaattgctgatttcettccg } \\
\text { tcg }\end{array}$ & $\operatorname{miR} 168$ & $\begin{array}{l}\text { ath-miR168a } \\
\text { deg-miR168* }\end{array}$ & $\begin{array}{l}\text { for cgccgetcgettggt } \\
\text { gcaggtcgggaa }\end{array}$ \\
\hline & & & & & $\begin{array}{l}\text { rev ctgatagttgggttctaaa } \\
\text { gatgcac }\end{array}$ & & & $\begin{array}{l}\text { for cgctcccgcettgca } \\
\text { ycaastga }\end{array}$ \\
\hline \multirow[t]{2}{*}{$A R F 8$} & $A R F 8$ & $\begin{array}{l}\text { Transcription factor } \\
\text { (AUXIN RESPONSE } \\
\text { FACTOR family) }\end{array}$ & $\begin{array}{l}\text { Hypocotyl } \\
\text { elongation, } \\
\text { flower and root } \\
\text { development }\end{array}$ & EF667342 & $\begin{array}{l}\text { for tagcgacagcatgcacatt } \\
\text { gga }\end{array}$ & $\operatorname{miR} 167$ & sly-miR167 & $\begin{array}{l}\text { for cgccgetgaagctg } \\
\text { ccagcatga }\end{array}$ \\
\hline & & & & & $\begin{array}{l}\text { rev tccggaaacgcattccaac } \\
\text { aga }\end{array}$ & & sly-miR167* & $\begin{array}{l}\text { for cgcgagatcatgtg } \\
\text { gcagcctta }\end{array}$ \\
\hline \multirow[t]{2}{*}{$N A C l$} & $N A C 1$ & $\begin{array}{l}\text { Transcription factor } \\
\text { (NAM/ATAF/CUC } \\
\text { domain-encoding } \\
\text { family) }\end{array}$ & $\begin{array}{l}\text { Lateral root } \\
\text { development }\end{array}$ & BG791220 & $\begin{array}{l}\text { for caccaggatttagattccat } \\
\text { cca }\end{array}$ & $\operatorname{miR} 164$ & ath-miR164a & $\begin{array}{l}\text { for cgccgctggagaag } \\
\text { cagggcacgtgca }\end{array}$ \\
\hline & & & & & rev tccttccetccaacacatgc & & deg-miR164* & $\begin{array}{l}\text { for cgtgcacgtgctch } \\
\text { hettctcca }\end{array}$ \\
\hline \multirow[t]{2}{*}{$H D-Z I P$} & $H D-Z I P$ protein & $\begin{array}{l}\text { Transcription factor } \\
\text { (class III HOMEO- } \\
\text { DOMAIN-LEUCINE } \\
\text { ZIPPER family) }\end{array}$ & $\begin{array}{l}\text { Leaf } \\
\text { morphogenesis }\end{array}$ & X91212 & $\begin{array}{l}\text { for ctgattagggagtctcctattct } \\
\text { ctc }\end{array}$ & $\operatorname{miR} 165 / 166$ & ath-miR165a & $\begin{array}{l}\text { for cgecgctcggacca } \\
\text { ggcttcatc }\end{array}$ \\
\hline & & & & & $\begin{array}{l}\text { rev gacacttgcttctgtaatcg } \\
\text { gtc }\end{array}$ & & deg-miR165* & $\begin{array}{l}\text { for ccggggamtgttgtc } \\
\text { tggmtcga }\end{array}$ \\
\hline \multirow[t]{2}{*}{ TCP3 } & TCP3 & $\begin{array}{l}\text { Transcription factor } \\
\text { (TB1/CYC/PCF } \\
\text { family) }\end{array}$ & $\begin{array}{l}\text { Leaf } \\
\text { morphogenesis }\end{array}$ & EF091574 & $\begin{array}{l}\text { for gectccatggaaaccaac } \\
\text { taccact }\end{array}$ & $\operatorname{miR} 319$ & sly-miR319 & $\begin{array}{l}\text { for ccgccgecttggact } \\
\text { gaagggagctcc }\end{array}$ \\
\hline & & & & & $\begin{array}{l}\text { rev gagctagcgctattgttctgcc } \\
\text { cta }\end{array}$ & & sly-miR319* & $\begin{array}{l}\text { for ccagctgccgcgag } \\
\text { cttctttagtcca }\end{array}$ \\
\hline \multirow[t]{2}{*}{ TCP4 } & TCP4/LANCEOLATE & $\begin{array}{l}\text { Transcription factor } \\
\text { (TB1/CYC/PCF } \\
\text { family) }\end{array}$ & $\begin{array}{l}\text { Leaf } \\
\text { morphogenesis }\end{array}$ & EF091571 & for agcaagtgcagggtcaagc & $\operatorname{miR} 319$ & sly-miR319 & $\begin{array}{l}\text { for ccgecgecttggact } \\
\text { gaagggagctcc }\end{array}$ \\
\hline & & & & & rev ctggtggcgaattgaacaag & & sly-miR319* & $\begin{array}{l}\text { for ccagctgccgcgag } \\
\text { cttctttagtcca }\end{array}$ \\
\hline \multirow[t]{2}{*}{$A G O 4$} & ARGONAUTE 4 & Ribonuclease $\mathrm{H}$ & $\begin{array}{l}\text { RNA-directed } \\
\text { DNA } \\
\text { methylation }\end{array}$ & $\mathrm{CD} 002775$ & $\begin{array}{l}\text { for tgtggctccgataagttatg } \\
\text { ccca }\end{array}$ & & & \\
\hline & & & & & rev tggagctagcaacgtttgaa & & & \\
\hline \multirow[t]{2}{*}{ PHAN } & ASI/PHANTASTICA & $\begin{array}{l}\text { MYB transcription } \\
\text { factor } \\
\text { [AS1/RS2/PHAN } \\
\text { (ARP) family] }\end{array}$ & $\begin{array}{l}\text { Leaf } \\
\text { morphogenesis }\end{array}$ & AF148934 & for aagcgctgagggaagaacag & & & \\
\hline & & & & & rev ccgccattaggttcagcaag & & & \\
\hline \multirow[t]{2}{*}{$T U B$} & $\beta$-TUBULIN & $\begin{array}{l}\text { (Reference gene for } \\
\text { mRNAs) }\end{array}$ & & DQ205342 & for cctgacagcttctgecatgt & & & \\
\hline & & & & & rev catcttcagcccagttggtg & & & \\
\hline \multirow[t]{3}{*}{$G A P D H$} & $\begin{array}{l}\text { GLYCERALDEHYDE } 3 \\
\text { PHOSPHATE } \\
\text { DEHYDROGENASE }\end{array}$ & $\begin{array}{l}\text { (Reference gene for } \\
\text { miRNAs) }\end{array}$ & & U97257 & $\begin{array}{l}\text { for cgccgcgaaacaatcaaac } \\
\text { tttac }\end{array}$ & & & \\
\hline & & & & & & & Poly(T) adapter & $\begin{array}{l}\text { gcgagcacagaattaata } \\
\text { cgactcactatagg }(\mathrm{t}) 1 \\
2 \mathrm{vn}\end{array}$ \\
\hline & & & & & & & $\begin{array}{l}\text { Poly }(\mathrm{T}) \text { adapter } \\
\text { reverse }^{\mathrm{d}}\end{array}$ & $\begin{array}{l}\text { gcgagcacagaattaata } \\
\text { cgact }\end{array}$ \\
\hline
\end{tabular}

${ }^{\text {a }}$ For, forward primer; rev, reverse primer.

${ }^{\mathrm{b}}$ All miRNA and miRNA* sequences derived from Sanger Institute; sly-, sequence from Solanum lycopersicum miRNA; ath-, sequence from Arabidopsis thaliana miRNA (when corresponding sly-miRNA not available on database); deg-, degenerated primer sequence complementary to corresponding miRNA* from Arabidopsis thaliana, Oryza sativa, Vitis vinifera, and Populus trichocarpa (when corresponding sly-miRNA* not available on database).

${ }^{c}$ Degenerated bases are indicated by the following one-letter code: $\mathrm{C}+\mathrm{T}=\mathrm{Y} ; \mathrm{C}+\mathrm{G}=\mathrm{S} ; \mathrm{A}+\mathrm{C}=\mathrm{M} ; \mathrm{A}+\mathrm{T}+\mathrm{C}=\mathrm{H} ; \mathrm{A}+\mathrm{C}+\mathrm{G}=\mathrm{V} ; \mathrm{A}+\mathrm{C}+\mathrm{G}+\mathrm{T}=\mathrm{N}$.

${ }^{\mathrm{d}}$ Common reverse primers for all miRNAs, miRNA*s, and tlyceraldehyde 3-phosphate dehydrogenase (GAPDH) reference sequence. 
ers (High-capacity reverse-transcription kit; Applied Biosystems, Foster City, CA, U.S.A.) in $20 \mu \mathrm{l}$ of total reaction volume containing $1 \mu \mathrm{g}$ of total RNA and incubated at $42^{\circ} \mathrm{C}$ for $2 \mathrm{~h}$ and at $85^{\circ} \mathrm{C}$ for $1 \mathrm{~min}$ according to the manufacturer's instructions.

On the same cDNA material, CMV RNA and host mRNA quantifications were performed via qRT-PCR. Primer pairs, used for qRT-PCR of viral RNAs 2 and 3, were designed to anneal to identical sequences between CMV-Fny and CMVLS, and were Fny_LS_RNA2 for (5'-tgagtttgcttggtgttatgacac-3', forward), Fny_LS_RNA2 rev (5'-catcaccttagcttccatgttgaa-3', reverse), Fny_LS_RNA3 for (5'-gtagacatctgtgacgcgatgccg-3', forward), and Fny_LS_RNA3 rev (5'-tcgcggagaagcatccatgagaa ag-3', reverse). Primers pairs used for tomato genes of interest were designed with the support of the Integrated DNA Technologies's PrimerQuest software and are listed in Table 2. Tomato $\beta$-tubulin, shown in preliminary analyses implemented in the software GeNorm (Vandesompele et al. 2002) to be stably expressed in healthy and virus-infected plants, was chosen as the reference endogenous gene for both viral RNA and mRNA relative quantification.

RT-PCR reaction volumes were set up to $10 \mu \mathrm{l}$ that contained Power SYBR Green PCR Master Mix (Applied Biosystems), $1 \mu \mathrm{l}$ of a 1:10 dilution of the cDNA reaction, and 300 $\mathrm{nM}$ each of the corresponding forward and reverse primers. Three different biological replicates, represented by total RNA extracted from two individually inoculated plants and converted into cDNA, were used for statistical analysis of the quantification, and each cDNA sample was amplified in duplicate on a single 48-well optical plate using a StepOne Real-Time PCR System (Applied Biosystems). The cycling profile consisted of $95^{\circ} \mathrm{C}$ for $10 \mathrm{~min}$ followed by 40 cycles of $15 \mathrm{~s}$ at $95^{\circ} \mathrm{C}$ and 70 $\mathrm{s}$ at $60^{\circ} \mathrm{C}$, as recommended by the manufacturer. Immediately after the final PCR cycle, a melting curve analysis was done to determine specificity of the reaction. Quantities of RNA accumulation levels were calculated as RQ values using the comparative cycle threshold $(\mathrm{Ct})\left(2^{-\Delta \Delta \mathrm{Ct}}\right)$ method (Livak and Schmittgen 2001). Before quantitative analyses, validation experiments were carried out to confirm equal amplification efficiencies between reference and target genes and the applicability of the comparative method. Assessing the relative amplification efficiencies was achieved by running standard curves for each amplicon (i.e., five serial $\log _{10}$ dilutions of starting cDNA were amplified and $\mathrm{Ct}$ values of target and reference genes were measured in triplicate and plotted against the $\log$ of the input cDNA amount). The efficiencies were considered comparable when falling within a range of $100 \pm$ $10 \%$, corresponding to a curve slope of $-3.3 \pm 0.33$ (Livak 1997), and primers pairs that did not allow PCR performances matching these criteria were discarded and substituted.

For qRT-PCR of miRNAs, the strategy of Shi and Chiang (2005) was adopted, with some modifications. The same total RNA preparations used for cDNA synthesis were polyadenylated as follows: $2 \mu \mathrm{g}$ of RNA was added to $25 \mu \mathrm{l}$ of a reaction mixture containing $2.5 \mathrm{mM} \mathrm{MnCl} 2,80 \mu \mathrm{M}$ ATP, $1 \times$ reaction buffer, and $0.5 \mu \mathrm{l}(1 \mathrm{U})$ of Escherichia coli Poly(A) Polymerase from Ambion's Poly(A) Tailing Kit (Applied Biosystems). The reaction was incubated at $37^{\circ} \mathrm{C}$ for $15 \mathrm{~min}$ in order to add a short adenine tail to non-poly(A), low molecular weight RNA molecules. Then, $4 \mu \mathrm{l}(320 \mathrm{ng})$ of this Poly (A) RNA was primed with 7.2 $\mu \mathrm{M}$ Poly(T) adapter (Table 2) and reverse transcribed in $10 \mu \mathrm{l}$ with the High-capacity reverse-transcription kit (Applied Biosystems) using the following temperature conditions: $10 \mathrm{~min}$ at $25^{\circ} \mathrm{C}, 50 \mathrm{~min}$ at $42^{\circ} \mathrm{C}$, and $1 \mathrm{~min}$ at $85^{\circ} \mathrm{C}$. For PCR amplification of miRNAs, a common reverse primer was employed named Poly(T) adapter reverse (Table 2), homologous to $23 \mathrm{nt}$ in the Poly(T) adapter sequence, while forward primers sequences were homologous to the positive- or negative-sense (star strand) miRNA, as obtained from the specific database available online from the Sanger Institute website. Forward primers included a 6-nt additional sequence at the $5^{\prime}$ terminus for stabilizing the amplicon, as described in Table 2. Forward primers for miRNA with no tomato sequences yet available on the database were designed either on the corresponding $A$. thaliana sequence or were degenerated by inserting multiple nucleotides at single positions in order to match the corresponding miRNA sequences from A. thaliana, Oryza sativa, Vitis vinifera, and Populus trichocarpa (Table 2). Tomato glyceraldehyde 3-phosphate dehydrogenase (GAPDH), whose stable expression in healthy versus infected plants was assessed by $\mathrm{Ge}$ Norm, was used as the reference gene for miRNA qRT-PCR: an amplicon of the same size of RT-PCR-amplified miRNAs was generated by using a forward primer homologous to the 3 '-terminal sequence of the GAPDH mRNA (Table 2). Amplification of miRNA targets was performed from $1 \mu$ of a 1:10 dilution of the cDNA reaction, in a volume of $10 \mu$ l containing $200 \mathrm{nM}$ primers and reagents from the Fast SYBR Green Master Mix (Applied Biosystems), and the cycling profile consisted of $95^{\circ} \mathrm{C}$ for $30 \mathrm{~s}$ followed by 40 cycles of $3 \mathrm{~s}$ at $95^{\circ} \mathrm{C}$ and $15 \mathrm{~s}$ at $60^{\circ} \mathrm{C}$, as recommended by the manufacturer. Also, for miRNA qRT$\mathrm{PCR}$ reactions, before quantitative analysis with the comparative method, equal amplification efficiencies were calculated by comparing standard curves (discussed above), and melting curve analyses were performed to monitor primer-dimer formation and to confirm individual gene-specific products.

\section{ACKNOWLEDGMENTS}

This work was supported by the MIUR project "GenoPOM", the CNR grant DG.RSTL.107.002, and the grant MIUR PRIN 2006. We thank F. Misceo, G. Schiraldi, and E. Santovito for their very valuable help with the laboratory work.

\section{LITERATURE CITED}

Aliyari, R., and Ding, S. W. 2009. RNA-based viral immunity initiated by the Dicer family of host immune receptors. Immunol. Rev. 227:176-188.

Bazzini, A. A., Hopp, H. E., Beachy, R. N., and Asurmendi, S. 2007. Infection and coaccumulation of Tobacco mosaic virus proteins alter microRNA levels, correlating with symptom and plant development. Proc. Natl. Acad. Sci. U.S.A. 104:12157-12162.

Beclin, C., Berthome, R., Palauqui, J. C., Tepfer, M., and Vaucheret, H. 1998. Infection of tobacco or Arabidopsis plants by CMV counteracts systemic post-transcriptional silencing of nonviral (trans)genes. Virology 252:313-317.

Brigneti, G., Voinnet, O., Li, W. X., Ji, L. H., Ding, S. W., and Baulcombe, D. C. 1998. Viral pathogenicity determinants are suppressors of transgene silencing in Nicotiana benthamiana. EMBO (Eur. Mol. Biol. Organ.) J. 17:6739-6746.

Chapman, E. J., and Carrington, J. C. 2007. Specialization and evolution of endogenous small RNA pathways. Nat. Rev. Genet. 8:884-896.

Chapman, E. J., Prokhnevsky, A. I., Gopinath, K., Dolja, V. V., and Carrington, J. C. 2004. Viral RNA silencing suppressors inhibit the microRNA pathway at an intermediate step. Genes Dev. 18:1179-1186.

Chitwood, D. H., Guo, M., Nogueira, F. T., and Timmermans, M. C. 2007. Establishing leaf polarity: The role of small RNAs and positional signals in the shoot apex. Development 134:813-823.

Chuck, G., Candela, H., and Hake, S. 2009. Big impacts by small RNAs in plant development. Curr. Opin. Plant Biol. 12:81-86.

Cillo, F., Finetti-Sialer, M. M., Papanice, M. A., and Gallitelli, D. 2004. Analysis of mechanisms involved in the Cucumber mosaic virus satellite RNA-mediated transgenic resistance in tomato plants. Mol. PlantMicrobe Interact. 17:98-108.

Cillo, F., Pasciuto, M. M., De Giovanni, C., Finetti-Sialer, M. M., Ricciardi, L., and Gallitelli, D. 2007. Response of tomato and its wild relatives in the genus Solanum to Cucumber mosaic virus and satellite RNA combinations. J. Gen. Virol. 88:3166-3176.

Collinge, M., and Boller, T. 2001. Differential induction of two potato genes, Stprx 2 and StNAC, in response to infection by Phytophthora infestans and to wounding. Plant Mol. Biol. 46:521-529.

Ding, S. W., Anderson, B. J., Haase, H. R., and Symons, R. H. 1994. New 
overlapping gene encoded by the cucumber mosaic virus genome. Virology 198:593-601.

Ding, S. W., Li, W. X., and Symons, R. H. 1995. A novel naturally occurring hybrid gene encoded by a plant RNA virus facilitates long distance virus movement. EMBO (Eur. Mol. Biol. Organ.) J. 14:5762-5772.

Ding, S. W., Shi, B. J., Li, W. X., and Symons, R. H. 1996. An interspecies hybrid RNA virus is significantly more virulent than either parental virus. Proc. Natl. Acad. Sci. U.S.A. 93:7470-7474.

Du, Z., Chen, F., Zhao, Z., Liao, Q., Palukaitis, P., and Chen, J. 2008. The $2 \mathrm{~b}$ protein and the $\mathrm{C}$-terminus of the $2 \mathrm{a}$ protein of cucumber mosaic virus subgroup I strains both play a role in viral RNA accumulation and induction of symptoms. Virology 380:363-370.

Dunoyer, P., Lecellier, C. H., Parizotto, E. A., Himber, C., and Voinnet, O. 2004. Probing the microRNA and small interfering RNA pathways with virus-encoded suppressors of RNA silencing. Plant Cell 16:1235-1250.

Feng, J., Wang, K., Liu, X., Chen, S., and Chen, J. 2009. The quantification of tomato microRNAs response to viral infection by stem-loop real-time RT-PCR. Gene 437:14-21.

Garcia, D. 2008. A miracle in plant development: Role of microRNAs in cell differentiation and patterning. Semin. Cell Dev. Biol. 19:586-595.

Hamilton, A., Voinnet, O., Chappell, L., and Baulcombe, D. 2002. Two classes of short interfering RNA in RNA silencing. EMBO (Eur. Mol. Biol. Organ.) J. 21:4671-4679.

Ji, L. H., and Ding, S. W. 2001. The suppressor of transgene RNA silencing encoded by Cucumber mosaic virus interferes with salicylic acidmediated virus resistance. Mol. Plant-Microbe Interact. 14:715-724.

Jones, L., Keining, T., Eamens, A., and Vaistij, F. E. 2006. Virus-induced gene silencing of argonaute genes in Nicotiana benthamiana demonstrates that extensive systemic silencing requires Argonaute1-like and Argonaute4-like genes. Plant Physiol. 141:598-606.

Jones-Rhoades, M. W., Bartel, D. P., and Bartel, B. 2006. MicroRNAS and their regulatory roles in plants. Annu. Rev. Plant Biol. 57:19-53.

Kasschau, K. D., Xie, Z., Allen, E., Llave, C., Chapman, E. J., Krizan, K. A., and Carrington, J. C. 2003. P1/HC-Pro, a viral suppressor of RNA silencing, interferes with Arabidopsis development and miRNA unction. Dev. Cell 4:205-217.

Kidner, C. A., and Martienssen, R. A. 2004. Spatially restricted microRNA directs leaf polarity through ARGONAUTE1. Nature 428:81-84.

Lewsey, M., Robertson, F. C., Canto, T., Palukaitis, P., and Carr, J. P. 2007. Selective targeting of miRNA-regulated plant development by a viral counter-silencing protein. Plant J. 50:240-252.

Li, H. W., Lucy, A. P., Guo, H. S., Li, W. X., Ji, L. H., Wong, S. M., and Ding, S. W. 1999. Strong host resistance targeted against a viral suppressor of the plant gene silencing defence mechanism. EMBO (Eur. Mol. Biol. Organ.) J. 18:2683-2691.

Livak, K. 1997. ABI Prism 7700 sequence detection system, User Bulletin 2. PE Applied Biosystems, Foster City, CA, U.S.A.

Livak, K. J., and Schmittgen, T. D. 2001. Analysis of relative gene expression data using real-time quantitative PCR and the 2(-Delta Delta $\mathrm{C}(\mathrm{T})$ ) method. Methods 25:402-408.

Llave, C., Kasschau, K. D., Rector, M. A., and Carrington, J. C. 2002. Endogenous and silencing-associated small RNAs in plants. Plant Cell 14:1605-1619.

Lot, H., Marrou, J., Quiot, J. B., and Esvan, C. H. 1972. Contribution à l'étude du virus da la masaique du cocombre (CMV). II. Méthode rapide de purification du virus. Ann. Phytopathol. 4:25-38.

Martin, R., Arenas, C., Daros, J. A., Covarrubias, A., Reyes, J. L., and Chua N. H. 2007. Characterization of small RNAs derived from Citrus exocortis viroid (CEVd) in infected tomato plants. Virology 367:135-146.

Nurmberg, P. L., Knox, K. A., Yun, B. W., Morris, P. C., Shafiei, R., Hudson, A., and Loake, G. J. 2007. The developmental selector AS1 is an evolutionarily conserved regulator of the plant immune response. Proc. Natl. Acad. Sci. U.S.A. 104:18795-18800.

Oh, S. K., Lee, S., Yu, S. H., and Choi, D. 2005. Expression of a novel NAC domain-containing transcription factor (CaNAC1) is preferentially associated with incompatible interactions between chili pepper and pathogens. Planta 222:876-887.

Olsen, A. N., Ernst, H. A., Leggio, L. L., and Skriver, K. 2005. NAC transcription factors: Structurally distinct, functionally diverse. Trends Plant Sci. 10:79-87.

Ori, N., Cohen, A. R., Etzioni, A., Brand, A., Yanai, O., Shleizer, S., Menda, N., Amsellem, Z., Efroni, I., Pekker, I., Alvarez, J. P., Blum, E., Zamir, D., and Eshed, Y. 2007. Regulation of LANCEOLATE by miR319 is required for compound-leaf development in tomato. Nat. Genet. 39:787-791.

Owen, J., and Palukaitis, P. 1988. Characterization of cucumber mosaic virus. I. Molecular heterogeneity mapping of RNA 3 in eight CMV strains. Virology 166:495-502.

Palukaitis, P., and Garcia-Arenal, F. 2003. Cucumoviruses. Pages 241-323 in: Advances in Virus Research, Vol 62.
Palukaitis, P., and MacFarlane, S. 2006. Viral counter-defense molecules. Pages 165-185 in: Natural Resistance Mechanisms of Plants to Viruses.

Qu, F., and Morris, T. J. 2005. Suppressors of RNA silencing encoded by plant viruses and their role in viral infections. FEBS (Fed. Eur. Biochem. Soc.) Lett. 579:5958-5964.

Qu, F., Ye, X., and Morris, T. J. 2008. Arabidopsis DRB4, AGO1, AGO7, and RDR6 participate in a DCL4-initiated antiviral RNA silencing pathway negatively regulated by DCL1. Proc. Natl. Acad. Sci. U.S.A. 105:14732-14737.

Rhoades, M. W., Reinhart, B. J., Lim, L. P., Burge, C. B., Bartel, B., and Bartel, D. P. 2002. Prediction of plant microRNA targets. Cell 110:513520.

Rizzo, T. M., and Palukaitis, P. 1990. Construction of full-length cDNA clones of cucumber mosaic virus RNAs 1, 2 and 3: Generation of infectious RNA transcripts. Mol. Gen. Genet. 222:249-256.

Selth, L. A., Dogra, S. C., Rasheed, M. S., Healy, H., Randles, J. W., and Rezaian, M. A. 2005. A NAC domain protein interacts with tomato leaf curl virus replication accessory protein and enhances viral replication. Plant Cell 17:311-325.

Shi, B. J., Palukaitis, P., and Symons, R. H. 2002. Differential virulence by strains of Cucumber mosaic virus is mediated by the $2 \mathrm{~b}$ gene. Mol. Plant-Microbe Interact. 15:947-955.

Shi, B. J., Miller, J., Symons, R. H., and Palukaitis, P. 2003. The 2b protein of cucumoviruses has a role in promoting the cell-to-cell movement of pseudorecombinant viruses. Mol. Plant-Microbe Interact. 16:261-267.

Shi, R., and Chiang, V. L. 2005. Facile means for quantifying microRNA expression by real-time PCR. Biotechniques 39:519-525.

Shiboleth, Y. M., Haronsky, E., Leibman, D., Arazi, T., Wassenegger, M., Whitham, S. A., Gaba, V., and Gal-On, A. 2007. The conserved FRNK box in HC-Pro, a plant viral suppressor of gene silencing, is required for small RNA binding and mediates symptom development. J. Virol. 81:13135-13148.

Soards, A. J., Murphy, A. M., Palukaitis, P., and Carr, J. P. 2002. Virulence and differential local and systemic spread of Cucumber mosaic virus in tobacco are affected by the CMV $2 \mathrm{~b}$ protein. Mol. Plant-Microbe Interact. 15:647-653.

Tagami, Y., Inaba, N., Kutsuna, N., Kurihara, Y., and Watanabe, Y. 2007. Specific enrichment of miRNAs in Arabidopsis thaliana infected with Tobacco mosaic virus. DNA Res 14:227-233.

Vandesompele, J., De Preter, K., Pattyn, F., Poppe, B., Van Roy, N., De Paepe, A., and Speleman, F. 2002. Accurate normalization of real-time quantitative RT-PCR data by geometric averaging of multiple internal control genes. Genome Biol. 3:RESEARCH0034.

Vaucheret, H., Vazquez, F., Crete, P., and Bartel, D. P. 2004. The action of ARGONAUTE1 in the miRNA pathway and its regulation by the miRNA pathway are crucial for plant development. Genes Dev. 18:1187-1197.

Voinnet, O. 2005. Induction and suppression of RNA silencing: Insights from viral infections. Nat. Rev. Genet. 6:206-220.

Wang, Y., Gaba, V., Yang, J., Palukaitis, P., and Gal-On, A. 2002. Characterization of synergy between Cucumber mosaic virus and potyviruses in cucurbit hosts. Phytopathology 92:51-58.

Wahyuni, W. S., Dietzgen, R. G., Hanada, K., and Francki, R. I. B. 1992. Serological and biological variation between and within subgroup I and II strains of cucumber mosaic virus. Plant Pathol. 41, 282-297.

Wang, Y., Tzfira, T., Gaba, V., Citovsky, V., Palukaitis, P., and Gal-On, A. 2004. Functional analysis of the Cucumber mosaic virus $2 \mathrm{~b}$ protein: Pathogenicity and nuclear localization. J. Gen. Virol. 85:3135-147.

Willmann, M. R., and Poethig, R. S. 2007. Conservation and evolution of miRNA regulatory programs in plant development. Curr. Opin. Plant Biol. 10:503-511

Ye, J., Qu, J., Zhang, J. F., Geng, Y. F., and Fang, R. X. 2009. A critical domain of the Cucumber mosaic virus $2 \mathrm{~b}$ protein for RNA silencing suppressor activity. FEBS (Fed. Eur. Biochem. Soc.) Lett. 583:101106.

Zhang, L., Handa, K., and Palukaitis, P. 1994. Mapping local and systemic symptom determinants of cucumber mosaic cucumovirus in tobacco. J. Gen. Virol. 75 (Pt. 11):3185-3191.

Zhang, X., Yuan, Y. R., Pei, Y., Lin, S. S., Tuschl, T., Patel, D. J., and Chua, N. H. 2006. Cucumber mosaic virus-encoded 2b suppressor inhibits Arabidopsis Argonaute1 cleavage activity to counter plant defense. Genes Dev. 20:3255-3268.

\section{AUTHOR-RECOMMENDED INTERNET RESOURCES}

Integrated DNA Technologies's PrimerQuest software: eu.idtdna.com/Scitools/Applications/Primerquest

Wellcome Trust Sanger Institute miRBase::Sequences database: microrna.sanger.ac.uk/sequences 